\title{
Can Rising Housing Prices Explain China's High Household Saving Rate?
}

Xin Wang and Yi Wen

China's average household saving rate is one of the highest in the world. One popular view attrib-
utes the high saving rate to fast-rising housing prices and other living costs in China. This article
uses simple economic logic to show that rising housing prices and living costs per se cannot explain
China's persistently high household saving rate. Although borrowing constraints and demograph-
ic changes can help translate housing prices to the aggregate saving rate, quantitative simulations
using Chinese data on household income, housing prices, and demographics indicate that rising
mortgage costs contribute at most 5 percentage points to the Chinese aggregate household saving
rate, given the down payment structure of China's mortgage markets. (JEL D14, D91, E21, I31, R21)

Federal Reserve Bank of St. Louis Review, March/April 2011, 93(2), pp. 67-87.

A

ccording to Friedman's (1957) permanent income hypothesis, rational consumers should save less when their income is growing fast because the need to save is reduced when people expect to be richer in the future than they are today. However, the reality in China is the opposite: China, as one of the fastest-growing economies, has an average household saving rate among the highest in the world.

"Aggregate household saving rate" is defined in this paper as the ratio of net changes in aggregate household financial wealth (e.g., bank deposits, government bonds, and stocks) to aggregate household disposable income. ${ }^{1}$ Figure 1 shows that the average Chinese household saving rate was around 2 percent in 1978 (the first year of economic reform) and rose rapidly thereafter. The saving rate stabilized at around 20 to 25 per-

1 Notice that our definition of the saving rate does not include changes in household nonfinancial wealth (such as housing investment). cent after the early 1990s and peaked in 1994 and 2003 with values of 27 percent and 26 percent, respectively.

Such a persistently high aggregate household saving rate is extraordinary compared with developed nations such as the United States, which has had an average household saving rate of 2 percent since the early 1990s. However, the high Chinese saving rate is not unique. Figure 2 shows the household saving rates for Japan and Korea in the postwar period. Both economies had a high household saving rate-above 20 percent-during their rapid economic growth periods (Japan in the mid-1970s and Korea from 1987 to 1994). ${ }^{2}$

2 These data are based on the Organisation for Economic Co-operation and Development database, Hayashi (1986), and Bai and Qian (2009). We are unable to find reliable household saving data for India. However, according to a report from the Centre for Monitoring Indian Economy, India's household saving rate (including investment in fixed assets) in 2001 was 24 percent. This number rose to 35 percent in 2007 and 36 percent in 2008. Based on such information, India's household saving rate has reached a level similar to China's.

Xin Wang is a doctoral student in the School of Economics and Management at Tsinghua University in Beijing, China. Yi Wen is an assistant vice president and economist at the Federal Reserve Bank of St. Louis and professor of economics at Tsinghua University. The authors thank Carlos Garriga, David Wheelock, Michael Z. Song, Weilong Zhang, and seminar participants at Tsinghua University and People’s University for helpful comments and Zhengjie Qian for sharing data.

(C) 2011, The Federal Reserve Bank of St. Louis. The views expressed in this article are those of the author(s) and do not necessarily reflect the views of the Federal Reserve System, the Board of Governors, or the regional Federal Reserve Banks. Articles may be reprinted, reproduced, published, distributed, displayed, and transmitted in their entirety if copyright notice, author name(s), and full citation are included. Abstracts, synopses, and other derivative works may be made only with prior written permission of the Federal Reserve Bank of St. Louis. 
Figure 1

\section{Chinese Household Saving Rate (1978-2006)}

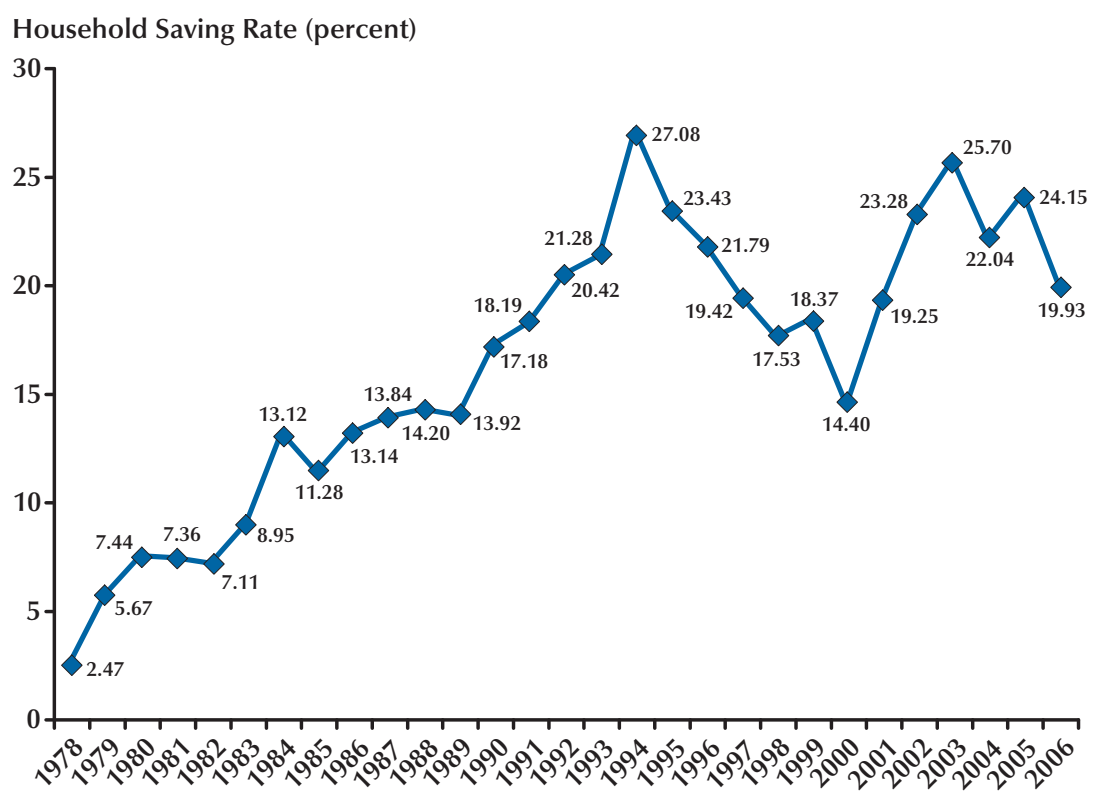

SOURCE: Bai and Qian (2009).

Figure 2

Cross-Country Comparison of Household Saving Rates (1968-2007)

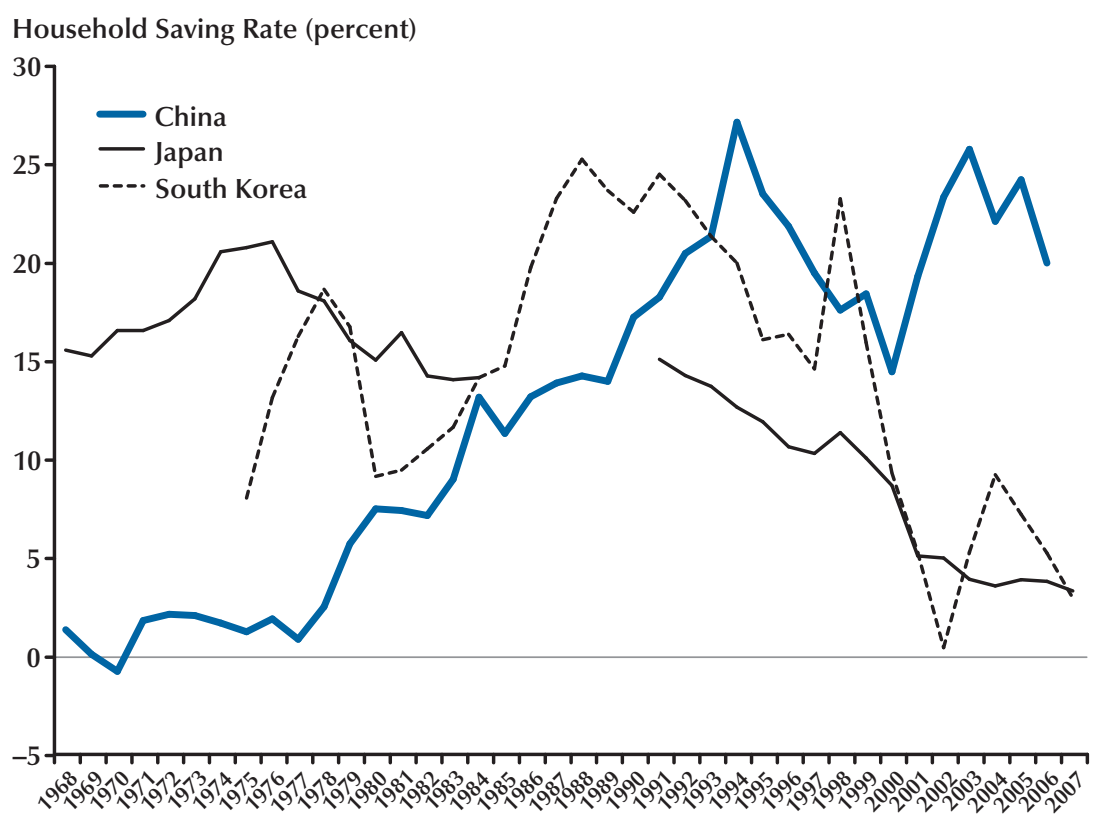


Why the Japanese saved so much during the rapid stage of economic development is still an open question (see, e.g., Hayashi, 1986). Hence, it is not surprising that the high Chinese saving rate appears puzzling, especially given China's rapid income growth.

The high saving rate of Chinese households not only poses a challenge to economic theory, but also has become a source of recent political controversy and trade disputes with the United States and its other major trading partners. For example, the former Chairman of the Federal Reserve, Alan Greenspan, alleged that the high Chinese saving rate was likely the culprit of the recent American subprime mortgage crisis because it caused low interest rates in the world financial markets, which pushed Americans toward excessive consumption and housing finance (Greenspan, 2009). Current Chairman Ben Bernanke (2005) also argued that the "global saving glut" is partly responsible for the increase in the U.S. current account deficit.

What are the causes of the high Chinese saving rate? A growing segment of the macro literature has focused on understanding this phenomenon. Many factors have been proposed as possible causes, including rapid income growth, aging population, lack of social safety nets and unemployment insurance, precautionary saving motives, cultural tradition of thrift, high costs of education and health care, and rising housing prices, among others. ${ }^{3}$ In particular, Wei and Zhang (2009) propose that the unbalanced sex ratio in China leads to competitive saving behavior in the marriage markets, which may significantly raise the aggregate household saving rate because men with adequate wealth accumulation (e.g., enough savings to buy houses) are more likely to attract marriage partners. Such competitive behavior further drives up housing prices and reinforces this competitive saving behavior. Chamon and Prasad (2010) argue that the rapidly rising private burdens of housing, education, and

\footnotetext{
3 This literature includes Modigliani and Cao (2004); Overland and Weil (2000); Horioka (1990); Horioka and Wan (2007); Chen, Imrohoroglu, and Imrohoroglu (2006); Song, Storesletten, and Zilibotti (2011); Yuan and Song (1999, 2000); and Wen (2009), among others.
}

health care are the most important contributing factors. They also conjecture that the impact of these factors on saving can be amplified by underdeveloped financial and credit markets.

Indeed, the rapidly rising housing prices and other living costs in China are serious socioeconomic problems and have attracted much attention from the news media and policymakers. In Beijing and Shanghai, for example, the average housing price-to-income ratio (for a 27.0-squaremeter [300-square-foot] living space) is about 12.4 Specifically, a young married couple needs to save their entire income (a 100 percent saving rate) for 12 years to afford a 55.74-square-meter (600square-foot) apartment. ${ }^{5}$ Hence, it is not surprising that rising housing prices have been perceived as one of the most important factors underlying China's high aggregate household saving rate.

But can rising housing prices really explain the persistently high household saving rate in China? This is not only an empirical question, but also a theoretical one with broad implications for developing economies. To the best of our knowledge, little theoretical work has been done to carefully and quantitatively address this question. Based on simple economic logic and quantitative analysis, our answer to this question is basically "No."

More specifically, we show the following:

- In the absence of economic growth and borrowing constraints, the aggregate household saving rate of an economy is independent of housing prices.

- Only under the following combined conditions will high housing prices significantly increase the aggregate household saving

\footnotetext{
4 According to China Statistical Yearbook (2007), in 2006 the average living space per person was 27.1 square meters (291.7 square feet) in urban areas and 30.7 square meters (323.9 square feet) in rural areas. However, the average living space for new homebuyers is greater than 30 square meters (322.9 square feet).

5 According to China Statistical Yearbook (2008), in 2007 the nationwide average housing price was 3,645 yuan per square meter, 10,661 yuan for Beijing, and 8,253 yuan for Shanghai. In 2007, the average disposable income per capita was 13,786 yuan nationwide, 21,989 yuan in Beijing, and 23,623 yuan in Shanghai. Hence, if the living space per person is 30 square meters (322.9 square feet), the ratio of housing price to disposable income would be 7.93 for the nation, 14.55 for Beijing, and 10.48 for Shanghai.
} 


\section{Wang and Wen}

rate: (i) Agents have severe borrowing constraints with zero possibility of obtaining mortgage loans, (ii) over time, the population of potential future homebuyers increases rapidly relative to current homebuyers, and (iii) housing prices rise faster than household income. However, these conditions are inconsistent with Chinese reality. Quantitative simulations based on Chinese time-series data for household income, housing prices, demographic structure, and mortgage down payment requirements show that rising housing prices can contribute at most 5 percentage points to the aggregate saving rate.

The intuition is simple: Suppose the only reason to save is to buy a house. Regardless of the level of housing prices, income saved for future housing purchases by future homebuyers (called "would-be homebuyers" in this paper) is always canceled by housing expenditures of the current homebuyers in the measured aggregate saving ratio. In other words, as soon as a person spends his or her past savings to purchase a good, the average lifetime saving rate for that individual immediately becomes zero. If part of the expenditure is financed by bank loans against the buyer's future income, the average lifetime saving rate at the moment of the home purchase is negative because the buyer must continue to save in the future to repay the loans until the debt is completely repaid. Hence, if the population is not growing and housing prices are constant, the aggregate saving rate across all cohorts at any point in time is independent of housing prices, regardless of borrowing constraints.

On the other hand, if housing prices are rapidly growing, then the population share of future homebuyers is effectively increasing relative to that of current homebuyers. In this case, the expenditures of the current homebuyers cannot completely cancel the savings of the would-be homebuyers. Because young cohorts need to save more and for longer periods under borrowing constraints when housing prices increase, this is equivalent to a continuous expansion of the population size of the saving cohort relative to the dissaving cohort. In other words, both housingprice growth and borrowing constraints are equivalent to population growth in terms of their impact on the aggregate saving rate. We call such equivalence the "population effect." Under such population effect, housing prices may play an important role in determining the aggregate saving rate. However, if household income increases at roughly the same rate as housing prices (as is the case in China), then the anticipated rising permanent income would reduce the need to save and cancels the population effect. In fact, the rapid growth in household income is the key force driving the rapidly rising housing prices in China, given the scarcity of habitable land in China.

Therefore, our analysis clarifies a popular confusion or misunderstanding that attributes the high aggregate household saving rate in China to rising housing prices and other costs of living. The same logic can also be applied to discredit similar theories that view the rising private burden in education, childbearing, health care, marriage, and so on in China as the major factors contributing to China's high aggregate household saving rate.

Our analysis also reveals a potential tension or conflict between survey data and economic analysis. Suppose survey data unambiguously indicate that cost-of-living factors are the primary motive for each household to increase its saving rate. Such empirical facts by no means imply that rising living costs are responsible for the persistently high aggregate household saving rate because incomes saved for any spending needs will always be consumed at later stages of life. Hence, such types of savings will cancel across households among different cohorts. Even if savings are not entirely spent within a person's lifetime and become bequests, they would reduce the children's need to save by exactly the same amount. Thus, any such type of savings should be canceled through aggregation across age cohorts.

Hayashi (1986) analyzes the possible causes of Japan's high household saving rate in the 1960s and 1970s. His analysis includes discussions regarding the possible impact of rising housing prices on the saving behavior of Japanese house- 
holds. In particular, using regression analysis, he finds that the average household saving rate of a given Japanese city is independent of that city's average housing prices. ${ }^{6}$ Based on this finding, Hayashi concludes that rising housing prices per se are not the cause of Japan's high household saving rate because of the "saving-expenditure cancellation" effects across population and age cohorts. This conclusion is similar to ours. However, Hayashi did not conduct detailed theoretical analysis to rigorously prove the point, so his analysis is not generalizable and may not apply to China. In particular, he did not consider the possibility that under severe borrowing constraints, rising housing prices may significantly increase the aggregate household saving rate.

In this paper, we choose a simple consumptionsaving model to illustrate our points, yet without the loss of generality. In the model, many variables (such as household income, housing prices, optimal age of homebuyers, and demographic structure) are deliberately kept exogenous so that comparative statistics can be easily obtained using Chinese data. The only endogenous optimization behavior derived from the model is consumption smoothing over a person's lifetime subject to borrowing constraints. This framework provides the simplest setup to calibrate the model using various Chinese time-series data.

The remainder of the paper is organized as follows. The next section presents a benchmark consumption-saving model without borrowing constraints and studies the effects of housing prices on the aggregate household saving rate. In subsequent sections we extend the analysis to include borrowing constraints, conduct robustness analysis, and consider other extensions of the basic model. The final section summarizes our findings and includes some policy recommendations.

\footnotetext{
${ }^{6}$ Hayashi also estimated the saving rates of homeowners, would-be homebuyers, and non-homeowners who do not plan to own houses in rural and urban areas. He argued that if housing prices have a significant impact on a household's saving rate, then the saving rate of would-be homebuyers should be significantly higher than the other two types of households, and urban households should have a higher saving rate than rural households. However, he did not find such differences in the Japanese data.
}

\section{THE BASIC MODEL}

\section{Constant Income and Housing Prices}

Suppose shelter (housing) is an indivisible and necessary consumption good that depreciates completely at the end of a homeowner's life. Given household income, increases in housing prices will force individual consumers to save more (and for a longer period) to afford a house. This positive association between housing prices and individual saving behavior may be why people view rising housing prices as a cause of the high aggregate saving rate in China. However, this view suffers from the fallacy of aggregation: It ignores the fact that when people purchase houses, they generate negative savings to society, canceling other people's positive savings.

More specifically, suppose that (i) the interest rate is zero and there is no discounting in the future, ${ }^{7}$ (ii) each individual's only purpose for saving at a young age is to buy a house in middle age, and (iii) there are no debts or bequests at birth or after death. Clearly, in such a society, each person's average lifetime saving rate should be exactly zero. Although a higher housing price will increase an individual's saving rate before purchasing a house, it does not change the average lifetime saving rate because at the moment of home purchase, all of the buyer's positive savings are exactly canceled by the current expenditure. Therefore, if the population is stable over time (i.e., each age cohort has the same number of individuals), then the aggregate saving rate is also zero, independent of housing prices.

Formally, imagine an economy where all agents have the same momentary utility function, and a typical consumer lives for $T$ periods with a constant income flow $\bar{Y}$ in each period. Each consumer needs to buy a house in period $t+1 \leq T,{ }^{8}$ the price of a house is $M>\bar{Y}$, and there are no borrowing constraints except the zero debt

\footnotetext{
7 Our results are robust to these assumptions.

8 Because $t$ can take arbitrary values, we can calibrate it using Chinese data. Making it endogenous complicates the analysis dramatically without additional gains. An additional advantage of keeping $t$ exogenous is that we need not worry about how and when housing enters the utility function. That is, we can ignore the utility value of housing without loss of generality.
} 
Table 1

Saving Behavior of Individual Consumers

\begin{tabular}{lccccccc} 
Period: & $\mathbf{1}$ & $\ldots$ & $\boldsymbol{t}$ & $\boldsymbol{t + 1}$ & $\boldsymbol{t + 2}$ & $\ldots$ & $\boldsymbol{T}$ \\
\hline Expenditure & $\bar{Y}-M / T$ & $\ldots$ & $\bar{Y}-M / T$ & $\bar{Y}-M / T+M$ & $\bar{Y}-M / T$ & $\ldots$ & $\bar{Y}-M / T$ \\
Savings & $M / T$ & $\ldots$ & $M / T$ & $\frac{M}{T}-M$ & $M / T$ & $\ldots$ & $M / T$ \\
Saving rate & $\frac{M}{T \bar{Y}}$ & $\ldots$ & $\frac{M}{T \bar{Y}}$ & $\frac{M}{T \bar{Y}}-\frac{M}{\bar{Y}}$ & $\frac{M}{T \bar{Y}}$ & $\ldots$ & $\frac{M}{T \bar{Y}}$ \\
\hline
\end{tabular}

requirement and the assumption of 100 percent depreciation of a house at the end of a homeowner's life. Naturally, we also need to assume $T \bar{Y}>M$ to ensure that each consumer is able to afford a house with his or her lifetime income. Under these conditions, because of the zero interest rate and no discounting, the marginal utility of consumption $(C)$ is exactly the same across time, so utility maximization implies that the consumer will save a constant amount of his or her personal income flow each period to smooth consumption.

Formally, the maximization problem is stated as follows:

$$
\begin{aligned}
& \max : \sum_{\tau=1}^{T} u\left(C_{\tau}\right) \\
& \text { s.t.: } \sum_{\tau=1}^{T} C_{\tau}+M \leq T \bar{Y} .
\end{aligned}
$$

Notice that we have deliberately omitted housing consumption in the utility function to simplify the analysis. This is an innocuous assumption because shelter is a necessary consumption good and the wealth effect generated from a house, if it exists, will only decrease the incentive for saving rather than increase it. The optimal solution to the above problem is

$$
C_{\tau}=\bar{Y}-\frac{M}{T} .
$$

That is, consumption is perfectly smoothed and equals a constant. However, notice that the total expenditure in period $t+1$ equals consumption plus the housing expenditure: $C_{t+1}+M$. This typical consumer's expenditure, savings, and saving rate in each period of his or her lifetime are reported in Table 1.

The first line of Table 1 indicates the consumer's living period (or age), the second line total expenditures in each period, the third line additional savings in each period, and the last line the saving rate in each period, which is defined as the ratio of additional savings to income.

Notice that the consumer's saving rate is always

$$
\frac{M}{T \bar{Y}}
$$

in each period except in period $t+1$. In period $t+1$, because of the additional expenditure of the housing purchase, the saving rate is negative,

$$
\frac{M}{T \bar{Y}}-\frac{M}{\bar{Y}}<0 \text {. }
$$

The consumer's average lifetime saving rate is

(1) Lifetime average saving rate $=\sum_{\tau=1}^{T} \frac{M}{T \bar{Y}}-\frac{M}{\bar{Y}}=0$.

Because the negative savings incurred at the moment of a home purchase exactly cancel the positive savings in the other periods, housing prices are irrelevant to the consumer's lifetime saving rate.

To compute the aggregate household saving rate in this economy with many different age cohorts for a particular period, we need to aggregate the saving rate of each age cohort in that period. There exist two measures (or definitions) of the aggregate saving rate: 
(i) The average of the personal saving rate across cohorts weighted by the population share of each age cohort-namely,

(2) $\bar{S}=\sum_{\tau=1}^{T} \alpha_{\tau} s_{\tau}$,

where $\alpha_{\tau}$ represents the population share of cohort $\tau$ in the total population, and

$$
s_{\tau}=\frac{S_{\tau}}{Y_{\tau}}
$$

represents the saving rate of $\operatorname{cohort} \tau$.

(ii) The ratio of aggregate saving to aggregate income in the same period:

$$
\bar{S}=\frac{\sum_{\tau=1}^{T} \alpha_{\tau} S_{\tau}}{\sum_{\tau=1}^{T} \alpha_{\tau} Y_{\tau}}
$$

where $\alpha_{\tau}$ still denotes the population share of cohort $\tau, S_{\tau}$ denotes the savings of cohort $\tau$, and $Y_{\tau}$ the income of cohort $\tau$.

We can call definition (i) the "average household saving rate" and definition (ii) the "aggregate household saving rate." Clearly, if all cohorts have the same income levels and identical population shares, the two definitions are equivalent. However, if different cohorts have different income levels and population shares (e.g., because of income growth and population growth), the two measures of the aggregate saving rate are not identical. Because definition (ii) depends only on macro data and is consistent with the data presented in Figures 1 and 2, we adopt definition (ii) in equation (3) as the measure of the aggregate household saving rate for the remainder of this paper.

Assume for a moment identical population shares across cohorts (we relax this assumption in the next section); then

$$
\alpha_{\tau}=\frac{1}{T}
$$

in equation (3). In this case, because income and housing prices are time invariant, we can compute the aggregate household saving rate in equation (3) using information provided in Table 1 to obtain
(4) $\bar{S}=\frac{\sum_{\tau=1}^{T} \frac{1}{T} S_{\tau}}{\sum_{\psi=1}^{T} \frac{1}{T} Y_{\tau}}=\frac{\left(\sum_{\tau=1}^{T} \frac{M}{T}\right)-M}{\sum_{\tau=1}^{T} \bar{Y}}=0$,

namely, the aggregate saving rate is zero and independent of housing prices.

Hence, under the maintained assumptions of constant income and demographics, changes in the level of housing prices do not affect the aggregate saving rate, although they do affect individuals' saving rates. In other words, even if 99 percent of the total population is saving for future home purchases, the other 1 percent (homebuyers) can generate just enough negative savings to cancel the would-be homebuyers' positive savings, resulting in a zero aggregate saving rate. This logic of aggregation is simple but not always recognized.

However, does the conclusion continue to hold if income and housing prices grow over time? In a sense, continuously rising housing prices imply that young cohorts must continuously increase their saving rate and save for a longer period to afford a house. Consequently, the relative population share of would-be homebuyers will become larger than that of current homebuyers (even without population growth), and this population effect may result in a positive aggregate saving rate, holding income constant. On the other hand, if income is also growing over time, the effective share of would-be homebuyers relative to homebuyers will shrink because the need to save is reduced (a negative population effect), everything else equal. Therefore, if income and housing prices are growing at the same time, their population effects may (at least partially) cancel each other, leading to insignificant changes in the aggregate saving rate. This issue is the focus of the next subsection.

\section{Time-Varying Income and Housing Prices}

In a model with time-varying income and housing prices, a consumer born in period 1 who needs to purchase a house in period $t+1$ solves the following problem: 
Table 2

\section{Saving Behavior of Different Age Cohorts}

\begin{tabular}{lccccccc} 
Age cohorts: & $\mathbf{1}$ & $\ldots$ & $\boldsymbol{t}$ & $\boldsymbol{t + 1}$ & $\boldsymbol{t + 2}$ & $\ldots$ & $\boldsymbol{T}$ \\
\hline Permanent income & $\bar{Y}_{t}$ & $\ldots$ & $\bar{Y}_{1}$ & $\bar{Y}_{0}$ & $\bar{Y}_{-1}$ & $\ldots$ & $\bar{Y}_{-T+t+1}$ \\
Housing price & $M_{t}$ & $\ldots$ & $M_{1}$ & $M_{0}$ & $M_{-1}$ & $\ldots$ & $M_{-T+t+1}$ \\
Savings & $M_{t} / T$ & $\ldots$ & $M_{1} / T$ & $\frac{(1-T) M_{0}}{T}$ & $M_{-1} / T$ & $\ldots$ & $M_{-T+t+1} / T$ \\
Saving rate & $M_{t}$ & $\ldots$ & $\frac{M_{1}}{T \bar{Y}_{1}}$ & $\frac{(1-T) M_{0}}{T \bar{Y}_{0}}$ & $\frac{M_{-1}}{T \bar{Y}_{-1}}$ & $\ldots$ & $\frac{M_{-T+t+1}}{T \bar{Y}_{-T+t+1}}$ \\
\hline
\end{tabular}

$$
\begin{aligned}
& \max : \sum_{\tau=1}^{T} u\left(C_{\tau}\right) \\
& \text { s.t.: } \sum_{\tau=1}^{T} C_{\tau}+M_{t+1} \leq \sum_{\tau=1}^{T} Y_{\tau} .
\end{aligned}
$$

The optimal solution is given by

$$
C_{\tau}=\bar{Y}-\frac{M_{t+1}}{T},
$$

where

$$
\bar{Y}=\frac{1}{T} \sum_{\tau=1}^{T} Y_{\tau}
$$

denotes a consumer's permanent income (i.e., average lifetime income). Total expenditure in period $t+1$ is $C+M_{t+1}$.

Suppose the optimal age for each consumer to become a homeowner is $t+1$ periods after birth. Suppose at the present moment this cohort of homebuyers faces housing price $M_{0}$ and has permanent income $\bar{Y}_{0}$. We call this age group "cohort $t+1$ " or "homebuyer cohort." Based on such notations, the generation one period younger than cohort $t+1$ is called "cohort $t$," who will become homebuyers in the next period and face housing price $M_{1}$ and permanent income $\bar{Y}_{1}$. Analogously, the generation one period older than the homebuyer cohort is called "cohort $t+2$," who have already bought a house one period ago when the housing price was $M_{-1}$ and permanent income was $\bar{Y}_{-1}$. Similarly, at the present moment all gen- erations younger than the homebuyer cohort are called cohorts $\{1,2, \ldots, t\}$; these consumers will face housing prices $\left\{M_{t}, M_{t-1}, \ldots, M_{1}\right\}$ and permanent income $\left\{\bar{Y}_{t}, \bar{Y}_{t-1}, \ldots, \bar{Y}_{1}\right\}$, respectively, when they purchase homes in the future. Also, at the moment all generations older than the homebuyers are called cohorts $\{t+2, t+3, \ldots, T\}$; and each person in these cohorts bought a house with price $\left\{M_{-1}, M_{-2}, \ldots, M_{-T+t-1}\right\}$ and permanent income $\left\{\bar{Y}_{-1}, \bar{Y}_{-2}, \ldots, \bar{Y}_{-T+t-1}\right\}$, respectively, in the past.

Based on the above notations, we can tabulate the incomes, savings, and saving rates of different age cohorts at the present moment. The first line in Table 2 shows the age of different cohorts at the present moment, the second line their respective permanent income levels, the third line the housing prices they face when becoming a homeowner, the fourth line their current level of savings, and the last line their respective saving rate at the present moment. The table shows that at the same time point different age cohorts have different saving rates because permanent income and housing prices are changing over time. However, regardless of age, the saving rate of each cohort is a function of the housing price-to-income ratio $(M / \bar{Y})$ facing that particular cohort.

Therefore, if the housing price-to-income ratio remains constant over time despite growing housing prices and permanent income, then different age cohorts (except the homebuyer cohort) have the same saving rate, whereas the home- 
buyer cohort always has a negative saving rate that offsets the positive savings of the other cohorts. Hence, the average saving rate across cohorts is exactly zero because each cohort is weighted identically by the factor $1 / T$ in computing the societal average saving rate.

However, because by definition the aggregate saving rate is the ratio of aggregate saving to aggregate income, instead of the weighted sum of individuals' saving rates, the measured aggregate saving rate is not necessarily zero but depends on the current housing price-to-aggregate income ratio. That is, the negative savings of the homebuyer cohort (cohort $t+1$ ) may receive a lower (or higher) weight than $1 / T$ if equation (3) is used as our measure of the aggregate saving rate. For example, if the ratio of cohort $t+1$ 's housing price $\left(M_{0}\right)$ to aggregate income equals $1 / T$, then the measured aggregate saving rate is still zero. However, if that ratio is greater than $1 / T$, then the measured aggregate saving rate is less than zero because the negative savings caused by the homebuyer cohort more than offsets the total savings from other cohorts due to time-varying housing prices and income; if that ratio is less than $1 / T$, the measured aggregate saving rate is positive.

To sort these effects, consider first the case in which permanent income and housing prices have constant growth rates according to the equations $\bar{Y}_{\tau}=(1+a) \bar{Y}_{\tau-1}$ and $M_{\tau}=(1+b) M_{\tau-1}$, respectively, where the growth rates $a$ and $b$ are both constants. Notice that if annual income grows at a constant rate, then the permanent income also grows at the same constant rate. Under these conditions, the aggregate saving rate is given by

$$
\bar{S}=\frac{\sum_{\tau=-T+t+1}^{t} \frac{1}{T} S_{\tau}}{\sum_{\tau=-T+t+1}^{t} \frac{1}{T} Y_{\tau}}=\frac{\left(\sum_{\tau=-T+t+1}^{t} \frac{M_{0}(1+b)^{\tau}}{T}\right)-M_{0}}{\sum_{\tau=-T+t+1}^{t} \bar{Y}_{0}(1+a)^{\tau}}
$$

If $a \neq 0$ and $b \neq 0$, equation (5) can be simplified to

$$
\bar{S}=\frac{M_{0}}{\bar{Y}_{0}} \frac{\frac{(1+b)^{-T+t+1}}{T} \frac{\left[1-(1+b)^{T}\right]}{1-(1+b)}-1}{(1+a)^{-T+t+1} \frac{\left[1-(1+a)^{T}\right]}{1-(1+a)}},
$$

which depends only on the housing price-toincome ratio of the current homebuyer cohort.

For example, suppose $a=b=10$ percent, $T=40$, and $t=15 .{ }^{9}$ Then equation (5) gives an aggregate saving rate of 2.14 percent, which is trivial compared with the 20 percent Chinese aggregate saving rate. On the other hand, it is possible to obtain an aggregate saving rate of 20 percent in the model if we allow the growth rate of permanent income and housing prices to be 50 percent per year, which is hard to imagine in reality. Therefore, when housing prices and permanent income grow at the same rate within an empirically plausible range, housing prices are still largely irrelevant to the aggregate saving rate.

Calibration 1. We now use actual Chinese data to calibrate the model. Suppose that people start working at age 21 and retire at age 60 ; thus, we set the total working years $T=40$. Also suppose that the average homebuyer's age is 35that is, people must work and save for 15 years before buying a house. This implies that $t=15$ in our model (e.g., in Table 2). Suppose that individuals in the homebuyer cohort (cohort $t+1$ ) become homeowners in the year 2007; in that year the housing price-to-income ratio in China was 7.93 , so we set $M_{0} / \bar{Y}_{0}=8$. According to the Chinese Statistical Yearbook (2008), from 1978 to 2007 the growth rate of average family income was 12.57 percent in rural areas and 13.58 percent in urban areas; hence we set $a=0.13$. According to the China Macroeconomic Information Network Database, the average growth rate of housing prices was 9.02 percent per year between 1991 and 2008; hence we set $b=0.09$. Entering these numbers into equation (5), the estimated aggregate saving rate equals 1 percent: That is, rising housing prices explain only 1 percentage point of China's aggregate household saving rate, substantially below the actual 27 percent saving rate in 2007.

Moreover, even if the growth rate of housing prices exceeds that of income, the impact of rising housing prices on the aggregate saving rate is still quite limited. For example, when the growth

$9 T=40$ and $t=15$ imply that each individual needs to work for 15 years to afford a house and work for 40 years to retire (income is assumed to be zero after retirement). 


\section{Wang and Wen}

rate of household income is 10 percent per year, the average growth rate of housing prices must be almost 20 percent per year to reach an aggregate saving rate of 20 percent in the model. Although a 20 percent annual growth rate in housing prices is possible for a short period, we have not seen such a high average growth rate over a 10-year period in China or anywhere else in the world.

Calibration 2. The above calibration analysis is based on the assumption that the growth rates of income and housing prices are constant over time. If we allow the growth rate of income and housing prices to vary over time, how does this affect our results? Because the simple model is no longer analytically tractable under uncertainty, we assume perfect foresight to gain intuition. When the growth rates of both income and housing prices are time varying, Table 2 implies that the aggregate household saving rate is determined by

(6)

$$
\bar{S}=\frac{\frac{1}{T} \sum_{\tau=-T+t+1}^{t} M_{\tau}-M_{0}}{\sum_{\tau=-T+t+1}^{t} \bar{Y}_{\tau}}
$$

As before, using 2007 as the base year for current homebuyers (cohort $t+1$ ), $M_{0}=P_{2007}$, where $P_{2007}$ denotes the average housing price in 2007. Recall that we use a 40-year window to compute the permanent income based on 40 years of average household income between year $2007-t$ and year $2007+T-t-1$, where $T=40$. For example, the permanent income of cohort $t+1$ is denoted by

$$
\bar{Y}_{0}=\frac{1}{T} \sum_{j=2007-t}^{2007+T-t-1} Y_{j}
$$

Using the same method, we can also estimate the permanent incomes of cohorts $\{1,2, \ldots, t\}$ and cohorts $\{t+2, t+3, \ldots, T\} .{ }^{10}$ By entering the estimated values of housing prices facing homebuyers of different age cohorts, $\left\{M_{t}, M_{t-1}, \ldots, M_{0}, \ldots, M_{-T+t-1}\right\}$, and the corresponding permanent incomes,

${ }^{10}$ Computing young cohorts' permanent income requires the use of income data after 2009. Since such data do not exist, we extrapolate by assuming a 10 percent annual growth rate after 2009 . We provide the sensitivity analyses in a later section.
$\left\{\bar{Y}_{t}, \bar{Y}_{t-1}, \ldots, \bar{Y}_{0}, \ldots, \bar{Y}_{-T+t-1}\right\}$, into equation (6), we obtain an aggregate saving rate of 0.61 percent. Therefore, regardless of how the model is calibrated, we conclude that in the absence of borrowing constraints, rising housing prices alone cannot explain China's aggregate household saving rate.

\section{BORROWING CONSTRAINTS AND DEMOGRAPHICS}

Our basic model makes two important assumptions: (i) Consumers can completely smooth their consumption over a working lifetime by using future income to finance current mortgage payments. (ii) The population or demographic structure does not change over time. These assumptions are not realistic and may bias our results.

Assumption (i) would be innocuous if household income, housing prices, and population were constant over time. To understand this point, suppose consumers cannot borrow at all. Then cohort $t+1$ must increase its saving rate at a younger age to accumulate just enough money to pay off the entire mortgage before period $t+1$. In this case, if income and housing prices do not grow over time, the aggregate saving rate is still zero because the negative savings generated by cohort $t+1$ in the housing market still completely cancel the total positive savings from cohorts $\{1,2, \ldots, t\}$. However, if income and housing prices grow over time, assumption (i) is no longer innocuous and borrowing constraints may greatly magnify the positive impact of housing prices on the aggregate saving rate.

The assumption of a constant population size does not allow our model to capture any transitional dynamics outside the steady state. Hence, the demographic structure is also important for the robustness of our analysis and conclusions and should be considered. Formal analyses with assumptions (i) and (ii) relaxed are presented below. We consider first the case with borrowing constraints and then the case with a time-varying population structure. 


\section{Table 3}

\section{Saving Behavior of Individuals under Borrowing Constraints*}

\begin{tabular}{|c|c|c|c|c|c|c|c|}
\hline Period: & 1 & $\ldots$ & $t$ & $t+1$ & $t+2$ & $\ldots$ & $T$ \\
\hline Expenditure & $\bar{Y}-M / t$ & $\ldots$ & $\bar{Y}-M / t$ & $\bar{Y}+M$ & $\bar{Y}$ & $\ldots$ & $\bar{Y}$ \\
\hline Savings & $M / t$ & $\ldots$ & $M / t$ & $-M$ & 0 & $\ldots$ & 0 \\
\hline Saving rate & $\frac{M}{t \bar{Y}}$ & $\cdots$ & $\frac{M}{t \bar{Y}}$ & $\frac{-M}{\bar{Y}}$ & 0 & $\ldots$ & 0 \\
\hline
\end{tabular}

NOTE: *Constant income and housing prices.

\section{Table 4}

\section{Saving Behavior of Different Age Cohorts under Borrowing Constraints*}

\begin{tabular}{|c|c|c|c|c|c|c|c|}
\hline Age cohorts: & 1 & $\ldots$ & $t$ & $t+1$ & $t+2$ & $\ldots$ & $T$ \\
\hline Permanent income & $\bar{Y}_{t}$ & $\cdots$ & $\bar{Y}_{1}$ & $\bar{Y}_{0}$ & $\bar{Y}_{-1}$ & $\cdots$ & $\bar{Y}_{-T+t+1}$ \\
\hline Housing price & $M_{t}$ & $\cdots$ & $M_{1}$ & $M_{0}$ & $M_{-1}$ & $\cdots$ & $M_{-T+t+1}$ \\
\hline Savings & $M_{t} / t$ & $\ldots$ & $M_{1} / t$ & $-M_{0}$ & 0 & $\ldots$ & 0 \\
\hline Saving rate & $\frac{M_{t}}{t \bar{Y}_{t}}$ & $\cdots$ & $\frac{M_{t}}{T \bar{Y}_{t}}$ & $\frac{-M_{0}}{\bar{Y}_{0}}$ & 0 & $\ldots$ & 0 \\
\hline
\end{tabular}

NOTE: *Time-varying income and housing prices.

\section{Borrowing Constraints}

To facilitate future analysis, we first consider constant income and housing prices under borrowing constraints. If agents cannot borrow at all and the optimal timing for purchasing a home is still $t+1$ periods after birth (we examine the robustness of the results to this assumption later), the would-be homebuyers must then increase their saving rates before period $t+1$. This implies that from period 1 to $t$ the saving rate is $M / t$, and optimal consumption is $\bar{Y}-M / t$. Between period $t+2$ and period $T$, the optimal consumption level is $\bar{Y}$ and the saving rate is zero. In period $t+1$, total expenditure (consumption plus housing pur- chase) is $\bar{Y}+M$. These statistics are summarized in Table 3.

Compared with Table 1, the addition of borrowing constraints raises the individual's saving rate from $M / T$ to $M / t$; however, the average lifetime saving rate is still zero. Hence, if the population share of each age cohort is the same, the aggregate saving rate is also zero.

Now with time-varying income and housing prices, the effective share of each cohort is no longer the same because of the population effect. In this case, we can use a method similar to that used for Table 2 to compute each age cohort's saving rate under borrowing constraints. These results are summarized in Table 4. 


\section{Wang and Wen}

Each generation purchases houses $t+1$ periods after birth. At a particular moment, the current homebuyer generation is called cohort $t+1$, and this cohort faces housing price $M_{0}$ and permanent income $\bar{Y}_{0}$. The one-period-younger generation is cohort $t$; this cohort will be buying houses in the next period, facing housing price $M_{1}$ and permanent income $\bar{Y}_{1}$, and this generation's current saving rate is $M_{1} / t$. Analogously, the one-period-older generation is cohort $t+2$; these individuals have already bought houses in the last period, faced housing price $M_{-1}$ and permanent income $\bar{Y}_{-1}$, and their current saving rate is 0 , in contrast to the model in Table 2 . All cohorts proceed in a similar fashion.

Suppose permanent income and housing prices grow over time according to the equations $\bar{Y}_{\tau}=(1+a) \bar{Y}_{\tau-1}$ and $M_{\tau}=(1+b) M_{\tau-1}$, respectively, where the growth rates $a$ and $b$ are both constant. Under such conditions, the aggregate saving rate is given by

$$
\bar{S}=\frac{\sum_{\tau=1}^{t} \frac{M_{0}(1+b)^{\tau}}{t}-M_{0}}{\sum_{\tau=-T+t+1}^{t} \bar{Y}_{0}(1+a)^{\tau}}
$$

which can be simplified to

$$
\bar{S}=\frac{M_{0}}{\bar{Y}_{0}} \frac{\frac{(1+b)}{t} \frac{\left[1-(1+b)^{t}\right]}{1-(1+b)}-1}{(1+a)^{-T+t+1} \frac{\left[1-(1+a)^{T}\right]}{1-(1+a)}} .
$$

It can be shown that the aggregate saving rate with borrowing constraints is larger than that without borrowing constraints. The intuition is as follows. Without borrowing constraints, when housing prices increase, the average saving rate of would-be homebuyers is larger than that of the current homeowners because of the population effect. With borrowing constraints, this population effect is significantly magnified because the saving rate of all homeowners is now zero. In other words, in computing the aggregate savings, the population weight of would-be homebuyers is increased from $1 / T$ to $1 / t$, while the population weight of the current homeowners is decreased from $1 / T$ to 0 . Because the aggregate income of all cohorts is the same, the ratio of aggregate savings to aggregate income (the aggregate saving rate) has increased under borrowing constraints.

Calibration. As in the previous analysis (with time-varying income and housing prices), we set $T=40, t=15, M_{0} / \bar{Y}_{0}=8, a=0.13$, and $b=0.09$. Substituting these values into equation (7) gives an aggregate saving rate of 16.66 percent. Alternatively, if we allow the growth rate of income and housing prices to vary over time (as in actual Chinese data), under the assumption of perfect foresight, the aggregate saving rate is given by

(8)

$$
\bar{S}=\frac{\frac{\sum_{\tau=1}^{t} M_{\tau}}{t}-M_{0}}{\sum_{\tau=-T+t+1}^{t} \bar{Y}_{\tau}}
$$

Using the same method adopted in a previous section, namely, choosing 2007 as the base year for the current homebuyers (cohort $t+1$ ), estimating and computing the associated values for housing prices $\left\{M_{t}, M_{t-1}, \ldots, M_{0}, \ldots, M_{-T+t-1}\right\}$ and permanent incomes $\left\{\bar{Y}_{t}, \bar{Y}_{t-1}, \ldots, \bar{Y}_{0}, \ldots, \bar{Y}_{-T+t-1}\right\}$, and substituting the results into equation (8) gives an aggregate saving rate of 19.22 percent, higher than that implied by equation (7).

Clearly, under severe borrowing constraints (i.e., no borrowing at all), using actual Chinese time-series data for housing prices and income implies estimates of the aggregate saving rate that match the actual Chinese household saving rate quite well. It thus appears that rising housing prices can explain China's high household saving rate if borrowing constraints are taken into account. But is this really the case?

Not really. In reality, the degrees of borrowing constraints are not as severe as assumed in the previous analysis. Typically, homebuyers need to pay only one-third of the housing price as a down payment and can borrow at least two-thirds with the mortgage. But how would a slightly relaxed borrowing constraint affect our quantitative result?

To be conservative, we assume that the down payment requirement is as high as 50 percent of 
Table 5

Saving Behavior of Individuals with 50 Percent Down Payment*

\begin{tabular}{|c|c|c|c|c|c|c|c|}
\hline Period: & 1 & $\ldots$ & $t$ & $t+1$ & $t+2$ & $\ldots$ & $\boldsymbol{T}$ \\
\hline Expenditure & $\bar{Y}-M / t$ & $\ldots$ & $\bar{Y}-M / t$ & $\bar{Y}+M$ & $\bar{Y}$ & $\ldots$ & $\bar{Y}$ \\
\hline Savings & $M / 2 t$ & $\ldots$ & $M / 2 t$ & $\frac{M}{2(T-t)}-M$ & $\frac{M}{2(T-t)}$ & $\cdots$ & $\frac{M}{2(T-t)}$ \\
\hline Saving rate & $\frac{M}{2 t \bar{Y}}$ & $\cdots$ & $\frac{M}{2 t \bar{Y}}$ & $\frac{M}{2(T-t) \bar{Y}}-\frac{M}{\bar{Y}}$ & $\frac{M}{2(T-t) \bar{Y}}$ & $\cdots$ & $\frac{M}{2(T-t) \bar{Y}}$ \\
\hline
\end{tabular}

NOTE: *Constant income and housing prices.

the house price. ${ }^{11}$ In this case, the borrowing constraints do not bind if each generation's optimal time for buying a house is after working for 20 years (because of sufficient savings). However, as long as each generation still needs to purchase houses after working for only 15 years (as assumed previously), borrowing constraints will still bind for every generation with an empirically plausible growth rate of income and housing prices. A typical individual's saving behavior given these conditions is shown in Table 5.

Between period 1 and period $t$ of an individual's lifetime, a consumer's annual saving is $M / 2 t$ (see Table 5 ); in period $t+1$, the total past savings are just enough to pay for the 50 percent down payment, so the consumer needs to borrow the other 50 percent from future income to pay for the mortgage. Thus, in period $t+1$ the buyer's housing expenditure is $M$ and saving is

$$
\frac{M}{2(T-t)}-M
$$

afterward, future saving for each period is always

$$
\frac{M}{2(T-t)} \text {. }
$$

\footnotetext{
${ }^{11}$ In China, the down payment required for home loans has been about one-third of the purchase price until recently. Now the down payment for the first house is one-third and that for the second house is one-half of the purchase price (some people in China own more than one home for investment purposes).
}

Based on such information and assuming time-varying income and housing prices, we can use the methods outlined in the previous sections to compute each cohort's saving rate at the same point of time (Table 6). As shown, if permanent income and housing prices follow a constant growth rule, $\bar{Y}_{\tau}=(1+a) \bar{Y}_{\tau-1}$ and $M_{\tau}=(1+b) M_{\tau-1}$, then the aggregate saving rate is given by

(9)

$$
\bar{S}=\frac{\sum_{\tau=1}^{t} \frac{M_{0}(1+b)^{\tau}}{2 t}+\sum_{\tau=-T+t+1}^{0} \frac{M_{0}(1+b)^{\tau}}{2(T-t)}-M_{0}}{\sum_{\tau=-T+t+1}^{t} \bar{Y}_{0}(1+a)^{\tau}}
$$

In such a case, we use Chinese data to set $T=40$, $t=15, M_{0} / \bar{Y}_{0}=8, a=0.13$, and $b=0.09$. Substituting these values into equation (9) gives an aggregate saving rate of 4.17 percent.

On the other hand, if the growth rates of income and housing prices are time varying, the aggregate saving rate is given by

(10)

$$
\bar{S}=\frac{\frac{\sum_{\tau=1}^{t} M_{\tau}}{2 t}+\frac{\sum_{\tau=-T+t+1}^{0} M_{\tau}}{2(T-t)}-M_{0}}{\sum_{\tau=-T+t+1}^{t} \bar{Y}_{\tau}} .
$$

Using the same method as before, by setting 2007 as the base year for homebuyers (cohort $t+1)$ and computing the associated housing prices $\left\{M_{t}, M_{t-1}, \ldots, M_{0}, \ldots, M_{-T+t-1}\right\}$ and permanent incomes 


\section{Table 6}

\section{Saving Behavior of Different Age Cohorts with 50 Percent Down Payment*}

\begin{tabular}{lccccccc} 
Age cohorts: & $\mathbf{1}$ & $\ldots$ & $\boldsymbol{t}$ & $\boldsymbol{t + 1}$ & $\boldsymbol{t + 2}$ & $\ldots$ & \multicolumn{1}{c}{} \\
\hline Permanent income & $\bar{Y}_{t}$ & $\ldots$ & $\bar{Y}_{1}$ & $\bar{Y}_{0}$ & $\bar{Y}_{-1}$ & $\ldots$ & $\bar{Y}_{-T+t+1}$ \\
Housing price & $M_{t}$ & $\ldots$ & $M_{1}$ & $M_{0}$ & $M_{-1}$ & $\ldots$ & $M_{-T+t+1}$ \\
Savings & $M_{t} / 2 t$ & $\ldots$ & $M_{1} / 2 t$ & $\frac{M_{0}}{2(T-t)}-M_{0}$ & $\frac{M_{-1}}{2(T-t)}$ & $\ldots$ & $\frac{M_{-T+t+1}}{2(T-t)}$ \\
Saving rate & $\frac{M_{t}}{2 t \overline{Y_{t}}}$ & $\ldots$ & $\frac{M_{1}}{2 t \bar{Y}_{1}}$ & $\frac{M_{0}}{2(T-t) \bar{Y}_{0}}-\frac{M_{0}}{\bar{Y}_{0}}$ & $\frac{M_{-1}}{2(T-t) \bar{Y}_{-1}}$ & $\ldots$ & $\frac{M_{-T+t+1}}{2(T-t) \bar{Y}_{-T+t+1}}$
\end{tabular}

NOTE: *Time-varying income and housing prices.

$\left\{\bar{Y}_{t}, \bar{Y}_{t-1}, \ldots, \bar{Y}_{0}, \ldots, \bar{Y}_{-T+t-1}\right\}$, equation (1) implies an aggregate saving rate of 4.34 percent.

We can make the following conclusions from the above analyses: Borrowing constraints can significantly amplify the positive effects of housing prices on the aggregate saving rate. However, as long as the borrowing constraints are not too severe (i.e., with a 50 percent down payment), ${ }^{12}$ the effects of rising housing prices on the aggregate saving rate are quite moderate, less than 5 percentage points.

Our analysis also indicates that, relative to rising housing prices and other living costs, borrowing constraints may play a more important role in explaining China's high household saving rate. This also explains why more than a decade of rising U.S. housing prices before the recent financial crisis did not induce a high household saving rate: American families are much less borrowing constrained than Chinese households. Our conclusion is consistent with the analysis of Wen (2009), who shows in a general equilibrium growth model that borrowing constraints not only induce a high precautionary saving rate under income uncertainty, but also make this precautionary saving rate an increasing function of income growth. Thus, a high income growth rate

\footnotetext{
12 The actual down payment requirement in China is less than 50 percent. Assuming a smaller value further reduces the impact of housing prices on the aggregate saving rate.
}

can lead to a high aggregate saving rate under borrowing constraints and income uncertainty.

\section{Demographics}

As with income and housing price changes, a changing population should have no impact on the aggregate saving rate without borrowing constraints. Thus, this section considers only cases with borrowing constraints.

If the population changes over time, the population weights $\alpha_{\tau}$ in equation (3) for different cohorts must be adjusted accordingly when computing the aggregate saving rate. Thus, if $W_{\tau}$ denotes cohort $\tau$ 's share in total population and assuming that permanent income and housing prices follow the equations $\bar{Y}_{\tau}=(1+a) \bar{Y}_{\tau-1}$ and $M_{\tau}=(1+b) M_{\tau-1}$, then the aggregate saving rate based on equation (3) is given by

$$
\bar{S}=\frac{\sum_{\tau=1}^{t} W_{\tau} \frac{M_{0}(1+b)^{\tau}}{t}-W_{0} M_{0}}{\sum_{\tau=-T+t+1}^{t} W_{\tau} \bar{Y}_{0}(1+a)^{\tau}},
$$

which is analogous to equation (7).

Based on the population shares of individuals 21 to 60 years of age provided in China Population and Employment Statistics Yearbook (2008), assuming that working ages are from 21 to 60 , the average homebuyer's age is 35 (i.e., he 


\section{Figure 3}

\section{Population Shares of Different Age Cohorts in 2007}

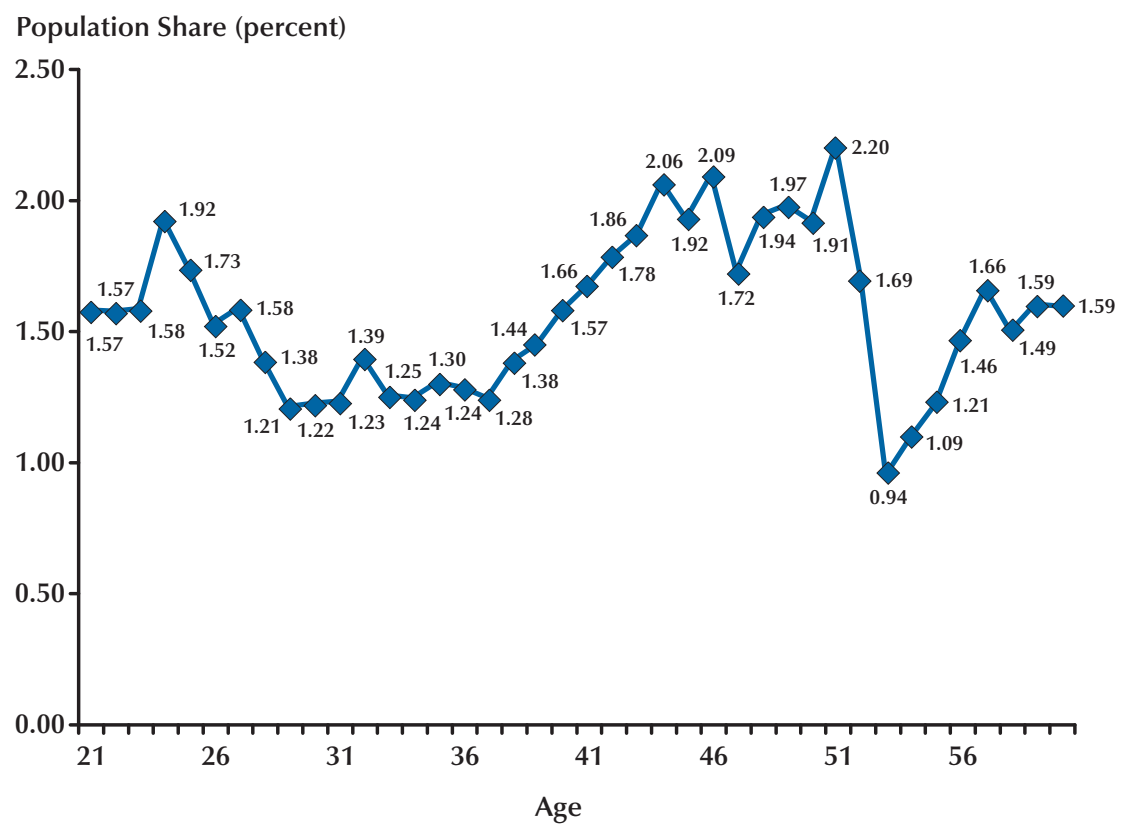

SOURCE: China Statistical Yearbook.

or she must work for 15 years to buy a house); using the average income growth and housing price growth in China, equation (11) implies an aggregate saving rate of 10.47 percent, lower than the value with constant population. If we allow a 50 percent down payment for the mortgage, the implied aggregate saving rate is negative $(-0.75$ percent), also lower than the value with constant population.

If we allow the growth rates of income and housing prices to vary over time, under 100 percent borrowing constraints (100 percent down payment), the aggregate saving rate is given by

$$
\bar{S}=\frac{\sum_{\tau=1}^{t} W_{\tau} \frac{M_{\tau}}{t}-W_{0} M_{0}}{\sum_{\tau=-T+t+1}^{t} W_{\tau} \bar{Y}_{\tau}}
$$

Using a similar calibration method as in the previous section by choosing 2007 as the base year for the homebuyer cohort, the implied aggregate saving rate is 11.32 percent, lower than the value with constant population. If we allow a 50 percent down payment, the implied aggregate saving rate is -1.62 percent, also lower than the value with constant population.

The reason that taking the demographic structure into account yields a lower aggregate saving rate, everything else equal, is that in recent years the homebuyer cohort is at its peak in terms of its population share. Therefore, the negative savings generated by this cohort receives larger weight than other cohorts. Figure 3 plots the demographic structure in China based on China Population and Employment Statistics Yearbook (2008), given the assumption that working ages are between 21 and 60 and the average homebuyer's age is 35 . The homebuyer cohort peaked around 2007.

If the base year of the homebuyer cohort is moved to other years, such as 2005 or earlier, or if we change the assumed age of homebuyers, the implied aggregate saving rate will differ only 
Table 7

\section{Aggregate Saving Rate under Different Assumptions}

\begin{tabular}{|c|c|c|}
\hline Assumptions & Equation & Saving rate $(\%)$ \\
\hline No $B C$, constant $\{\mathrm{D}, \mathrm{I}, \mathrm{P}\}$ & $(4)$ & 0.00 \\
\hline No BC, constant $D$, constant growth in $\{\mathrm{I}, \mathrm{P}\}$ & (5) & 1.00 \\
\hline No $B C$, constant $D$, time-varying growth in $\{I, P\}$ & (6) & 0.61 \\
\hline $100 \%$ BC, constant $\mathrm{D}$, constant growth in $\{I, P\}$ & (7) & 16.66 \\
\hline $100 \% B C$, constant $\mathrm{D}$, time-varying growth in $\{\mathrm{I}, \mathrm{P}\}$ & (8) & 19.22 \\
\hline $50 \%$ BC, constant $D$, constant growth in $\{I, P\}$ & (9) & 4.17 \\
\hline $50 \% \mathrm{BC}$, constant $\mathrm{D}$, time-varying growth in $\{\mathrm{I}, \mathrm{P}\}$ & $(10)$ & 4.34 \\
\hline Time-varying D, $100 \% \mathrm{BC}$, constant growth in $\{\mathrm{I}, \mathrm{P}\}$ & $(11)$ & 10.47 \\
\hline Time-varying $\mathrm{D}$ and growth in $\{\mathrm{I}, \mathrm{P}\}, 100 \% \mathrm{BC}$ & $(12)$ & 11.32 \\
\hline Time-varying $\mathrm{D}, 50 \% \mathrm{BC}$, constant growth in $\{\mathrm{I}, \mathrm{P}\}$ & & -0.75 \\
\hline Time-varying $\mathrm{D}$ and growth in $\{\mathrm{I}, \mathrm{P}\}, 50 \% \mathrm{BC}$ & & -1.62 \\
\hline
\end{tabular}

insignificantly from the values obtained above. The reason is simple: Unless the population has been sharply declining so that the population share of the homebuyer cohort is always significantly larger than that of the would-be homebuyer cohorts (which is inconsistent with Chinese data), taking the demographic structure into account cannot strengthen the effect of rising housing prices on the aggregate saving rate.

\section{Summary of Analyses}

The previous analyses covered three scenarios: (i) time-varying income and housing prices, (ii) borrowing constraints, and (iii) demographic changes. The results are briefly summarized in Table 7. The first column lists the assumptions, the second column shows the corresponding equation used to compute the aggregate saving rate, and the last column shows the numerical value of the aggregate saving rate.

The first three rows in Table 7 show that without borrowing constraints and demographic changes, rising housing prices contribute little to the aggregate saving rate: less than 1 percent. The subsequent two rows show that under complete borrowing constraints (with zero possibility to borrow), rising housing prices can have large effects on the aggregate saving rate, ranging from 16.66 to 19.22 percent. However, such effects are quickly dampened once the degree of borrowing constraints is reduced. For example, with a 50 percent down payment requirement, the aggregate saving rate is reduced to 4.17 percent and 4.34 percent, respectively, depending on the specific income process. In addition, if China's demographic structure is taken into account, the last two rows in the table show that the saving rate is reduced further: down to -0.75 percent and -1.62 percent, respectively. Therefore, given Chinese time-series data on household income, mortgage prices, borrowing costs, and demographics, we can conclude that the aggregate household saving rate is essentially unrelated to housing prices.

\section{MORE SENSITIVITY ANALYSES Different Extrapolations}

In the previous analyses, we extrapolated the future growth rates of permanent income and housing prices beyond 2009 when considering the effects of time-varying income and housing prices. For example, in equation (10) we assumed future growth rates of income and housing prices 


\section{Table 8}

\section{Sensitivity Analysis for Different Future Growth Rates*}

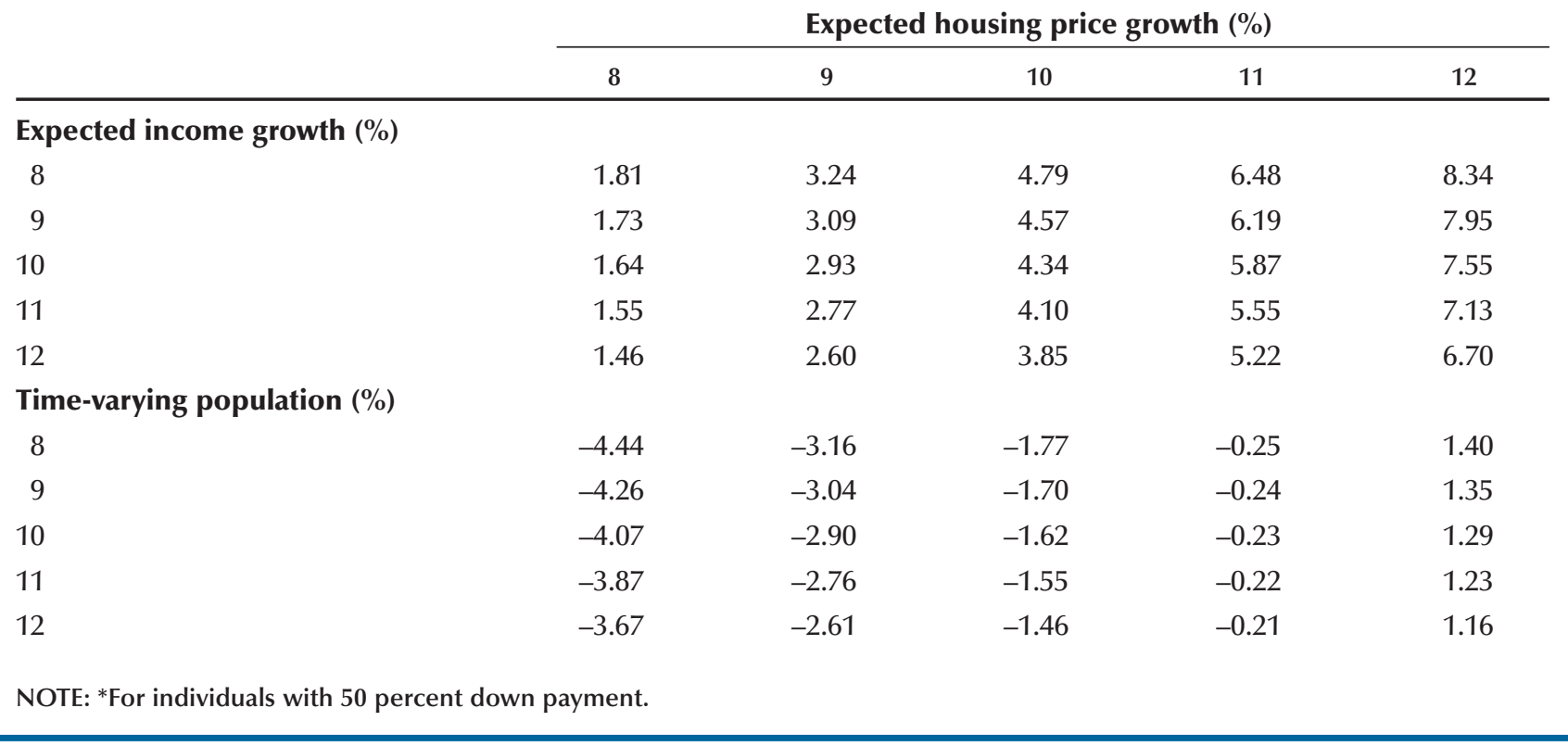

of 10 percent per year after 2009. In the following, we conduct sensitivity analyses on equation (10) by considering other possible growth rates for future income and housing prices. Let us assume a 50 percent down payment requirement and that future growth rates of income and housing prices take the values of 8 percent, 9 percent, 10 percent, 11 percent, and 12 percent, respectively. The implied aggregate saving rates under these possible future growth rates for income and housing prices are reported in Table 8, where the top panel assumes a constant demographic structure and the bottom panel considers a time-varying population.

First, Table 8 shows that, given the growth rate of housing prices (i.e., the columns), the aggregate saving rate decreases as the growth rate of income increases. This is consistent with the permanent income hypothesis. Second, the aggregate saving rate increases when housing prices are growing faster, given the income growth (i.e., the rows). The main reason for this increase is the existence of borrowing constraints. Third, the aggregate saving rate is highest (as high as 8.34 percent) when the expected future income growth rate is 8 percent and that of housing prices is 12 percent. However, if we reduce the down payment requirement from 50 percent to 33 percent, the aggregate saving rate becomes essentially zero. Even if the down payment remains 50 percent, taking into account China's demographic structure (lower panel in Table 8) also reduces the implied aggregate saving rate from 8.34 percent to 1.40 percent. Therefore, unless people expect that (i) housing prices will grow much faster than 12 percent per year, (ii) future income growth is significantly lower than 8 percent per year, and (iii) the borrowing constraints are more severe than the 50 percent down payment requirement, housing prices cannot explain China's persistently high aggregate household saving rate.

\section{Other Possible Extensions}

Our analysis so far is based on a simple economic model. However, our simple model can be further enriched. In this subsection, we discuss some possible extensions and the likely effects of such extensions on our results.

Endogenous Timing of Home Purchase. The optimal timing of home purchase $t$ in our model 
is exogenous and is calibrated using the average homebuyer's age (working years). If we can make this variable endogenous, the model has the potential to explain the difference in the optimal age of homebuyers across countries. However, even if this variable is endogenized, we still need to calibrate the other parameters so that the model-predicted timing of home purchase matches that in the data. This is not much different from exogenously setting $t=15$, as we did herein. Therefore, even if $t$ were endogenous, our results would still hold under similar calibrations.

Inclusion of Wealth Effects. In our simple model, a shelter is a pure consumption good and generates a constant lifetime utility. In reality, a shelter is also a capital good because it may yield capital gains when housing prices appreciate, which may generate positive wealth effects. However, this simplification does not hurt our analysis. If shelters were introduced into our model as a capital good (or durable consumption good), the situation is the same for the would-be homebuyer cohorts when the housing price increases; but for the current homeowners, it implies that their wealth would increase, which would decrease their saving incentives and mitigate the positive impact of rising housing prices on lifetime savings. Such a wealth effect may explain why the aggregate household saving rate in developed countries has been declining over the past decade. For example, Case, Quigley, and Shiller (2006), whose empirical analysis is based on U.S. cross-country and cross-state data, find that for every 10 percent increase in housing prices, the consumption-to-income ratio increases by 1.1 percent and the saving rate decreases by 1.1 percent. These authors explain their findings based on the wealth effect. Hence, introducing a wealth effect into our model would only strengthen our conclusion that rising housing prices cannot explain China's high aggregate saving rate.

Depreciation Less than 100 Percent. The previous analyses are based on the assumption that a house has zero market value at the end of a homeowner's life. This assumption is not realistic, but it is an innocuous assumption and does not affect our main results. The reason is simple:
If homeowners could sell houses at the end of their lifetimes, they could then borrow against the home equity to increase consumption when young and use the proceeds from mortgage sales to repay their debt at the end of life. This would effectively relax borrowing constraints and reduce each individual's saving rate before buying a house. More specifically, if the market value of the house does not change over time and can be collateralized, an individual would then have no need to save before purchasing a home, would incur a negative saving rate (or positive borrowing) equivalent to the market value of the house when purchasing a home, and would incur a positive saving rate when selling the home at the end of life. Thus, the average lifetime saving rate would still be zero.

The Hump-Shaped Curve of Lifetime Income. Our model assumes that household income is either constant or increasing over time, but in reality income follows a life cycle with an inverted-U shape: Personal income peaks in middle age. However, our results are not sensitive to this income pattern. First, in our model the measured income is household or family income, not individual income. Household income is less hump-shaped than individual income unless both husband and wife are identical wage earners. Second, and more important, the primary concern for a hump-shaped income profile is that agents are more borrowing constrained at a young age. But in our model we have set the optimal age of home purchase as 35 (i.e., 15 years after joining the workforce), which is roughly the peak year of lifetime income. Thus, our calibration makes the concern of borrowing constraints due to a hump-shaped income pattern less relevant. In addition, our calibration of the down payment requirement of 50 percent has effectively overestimated the actual degree of borrowing constraints; we showed that, even under a 50 percent down payment requirement, the influence of rising housing prices on the aggregate saving rate is insignificant. Hence, taking into account the inverted- $U$ curve of lifetime income should not change our results significantly.

Bequests. In China, many parents give money to their children to buy houses because the 
children cannot afford the high mortgage costs. Hence, one popular view is that such altruism raised China's aggregate saving rate. We can use a version of our simple model to show that this view is incorrect because it again suffers from the fallacy of aggregation. The intuition is simple: Bequests from parents reduce their children's need to save; hence, at the aggregate level, bequests may have little effect on the average household saving rate.

\section{CONCLUSION}

Our analysis shows the following: (i) Without borrowing constraints and population growth, the aggregate household saving rate is essentially independent of rising housing prices. (ii) Accounting for China's demographics reduces the aggregate saving rate because the ratio of homebuyers to non-homebuyers has been increasing, which increases the weights of the negative savings of the homebuyers in aggregate savings. (iii) Under borrowing constraints the aggregate saving rate can become quite sensitive to housing prices; however, with realistic degrees of borrowing constraints (such as allowing for a 50 percent down payment), rising housing prices can generate an aggregate saving rate of 4.17 percent without considering the Chinese demographic structure (this value becomes zero if the demographic structure is taken into account). These values are too small to explain China's 20 percent aggregate saving rate. Therefore, our analysis clarifies a popular misunderstanding or fallacy that attributes the rapidly rising costs of living, such as housing, education, health care, and so on, to China's high aggregate household saving rate. This view ignores the saving-expenditure cancellation effect across cohorts.
If the rapidly rising housing prices and other costs of living are not responsible for the persistently high Chinese saving rate, what factors actually cause such saving? We believe that large uninsurable uncertainty and severe borrowing constraints in conjunction with rapid income growth may provide the answer to China's high household saving rate. For example, Wen (2009) shows that when individuals face large uninsured idiosyncratic risk and severe borrowing constraints, their marginal propensity to save becomes a positive function of the growth rate of their permanent income. Thus, rapid income growth could imply an extremely high household saving rate when financial markets are incomplete. In particular, Wen (2009) shows that a standard buffer-stock saving model with incomplete financial markets could generate a 30 percent aggregate household saving rate when the income growth rate is 10 percent per year. In this case, an individual's expenditure does not completely cancel his or her precautionary saving because of the need for a buffer stock at any moment in life. In other words, it is optimal to always maintain a positive stock of personal saving as self-insurance against unpredictable shocks.

Our findings also have some policy implications. Although rapidly rising housing prices may have adverse welfare effects on would-be homebuyers, policies designed to reduce housing prices may be effective in reducing the individual saving rate of young people but will not be effective in reducing the aggregate saving rate. In comparison, policies designed to reduce borrowing constraints and improve the efficiency of the financial system may prove more effective in reducing the aggregate saving rate. 


\section{Wang and Wen}

\section{REFERENCES}

Bai, Chong-en and Qian, Zhenjie. "Factor Income Share in China: The Story Behind the Statistics." Economic Research, 2009, 3, pp. 27-41.

Bernanke, Ben S. "The Global Saving Glut and the U.S. Current Account Deficit.” Remarks by Governor Ben S. Bernanke at the Sandridge Lecture, Virginia Association of Economics, Richmond, Virginia, March 10, 2005; www.federalreserve.gov/boarddocs/speeches/2005/200503102/.

Carroll, Christopher D.; Overland, Jody and Weil, David N. "Saving and Growth with Habit Formation." American Economic Review, June 2000, 90(3), pp. 341-55.

Case, Karl E.; Quigley, John M. and Shiller, Robert J. "Comparing Wealth Effects: The Stock Market versus the Housing Market.” Berkeley Electronic Journal of Microeconomics: Advances in Macroeconomics, 2005, 5(1), Article 1.

Chamon, Marcos D. and Prasad, Eswar, S. "Why Are Saving Rates of Urban Households in China Rising?" American Economic Journal: Macroeconomics, January 2010, 2(1), pp. 93-130.

Chen, Kaiji; Imrohoroglu, Ayse and Imrohoroglu, Selahattin. “The Japanese Saving Rate.” American Economic Review, December 2006, 96(5), pp. 1850-58.

China Macroeconomic Network Database. www.macrochina.com.cn/english/index.shtml.

China Population and Employment Statistics Yearbook 2008. Beijing: China Statistics Press, 2008.

China Statistical Yearbook 2007. Beijing: China Statistics Press, 2007.

China Statistical Yearbook 2008. Beijing: China Statistics Press, 2008.

Friedman, Milton. A Theory of the Consumption Function. Princeton, NJ: Princeton University Press, 1957.

Greenspan, Alan. “The Fed Didn’t Cause the Housing Bubble.” Wall Street Journal, March 11, 2009, p. A15; http://online.wsj.com/article/SB123672965066989281.html.

Hayashi, Fumio. “Why Is Japan's Saving Rate So Apparently High?” in Stanley Fischer, ed., NBER Macroeconomics Annual 1986. Volume 1. Cambridge, MA: MIT Press, pp. 147-234.

He, Xinhua and Cao, Yongfu. "Understanding the High Saving Rate in China." China and World Economy, 2007, 15(1), pp. 1-13.

Horioka, Charles Y. "Why Is Japan's Household Saving Rate So High? A Literature Survey.” Journal of the Japanese and International Economics, March 1990, 4(1), pp. 49-92.

Horioka, Charles Y. and Wan, Hunmin. "The Determinants of Household Saving in China: A Dynamic Panel Analysis of Provincial Data." Journal of Money, Credit, and Banking, December 2007, 39(8), pp. 2077-96.

Modigliani, Franco and Cao, Shi L. "The Chinese Saving Puzzle and the Life-Cycle Hypothesis." Journal of Economic Literature, March 2004, 42(1), pp. 145-70. 
Song, Zheng; Storesletten, Kjetil and Zilibotti, Fabrizio. "Growing Like China." American Economic Review, February 2011, 101, pp. 196-233.

Wei, Shang-Jin and Zhang, Xiaobo. "The Competitive Saving Motive: Evidence from Rising Sex Ratios and Savings Rates in China.” NBER Working Paper No. 15093, National Bureau of Economic Research, June 2009; www.nber.org/papers/w15093.pdf.

Wen, Yi. "Saving and Growth under Borrowing Constraints: Explaining the 'High Saving Rate' Puzzle." Working Paper No. 2009-045C, Federal Reserve Bank of St. Louis, September 2009, revised June 2010; http://research.stlouisfed.org/wp/2009/2009-045.pdf.

Yuan, Zhigang and Song, Zheng. "Urban Consumption Behavior and China’s Economic Growth.” Economic Research Journal, 1999, 11, pp. 20-28 [in Chinese].

Yuan, Zhigang and Song, Zheng. "The Age Composition of Population, the Endowment Insurance System and Optimal Savings Ratio in China.” Economic Research Journal, 2000, 11, pp. 24-32 [in Chinese]. 
